\title{
Optimizing the procedure for mercury recovery from dental amalgam
}

\section{Flávia Godoy lano(a) \\ Ovídio dos Santos Sobrinho ${ }^{(b)}$ \\ Thelma Lopes da Silva ${ }^{(c)}$ \\ Marlus Alves Pereira ${ }^{(\mathrm{d})}$ \\ Paulo Jorge Moraes Figueiredo(e) \\ Leny Borghesan Albertini \\ Alberguini(f) \\ José Mauro Granjeiro(g)}

\begin{abstract}
Mercury, as any other heavy metal, may cause environmental damages due to its accumulation and biotransformation. Dental offices, whether private or institutional, use dental amalgam as a restorative material on a daily basis. Dental amalgam is composed of mercury $(50 \%)$, silver $(30 \%)$ and other metals. Approximately $30 \%$ of the amalgam prepared in dental offices ( $0.6 \mathrm{~g}$ per capsule) are wasted and inadequately discarded without any treatment. Methods for mercury recovery have been proposed previously, using high temperatures through exposure to direct flame $\left(650^{\circ} \mathrm{C}\right)$, long processing time, and hazardous reagents as potassium cyanide. The purpose of this study was to develop a method to replace the direct flame by an electrical mantle in the process of mercury recovery. Results showed an average mercury recovery of $90 \%$ from $2 \mathrm{~kg}$ of amalgam after 30 minutes of processing time, thus optimizing the procedure. The proposed modifications allowed a significant reduction in processing time and a mercury recovery with high purity. The modified process also provided minimization of operator exposure to physical, chemical and ergonomic hazards, representing a technological advance compared to the risks inherent to the original method. It also provided environmental health and economy of energy resources by replacing a finite energy source (fossil and organic) by a more environmentally appropriate electric source, resulting in significant improvement of the procedure for mercury recovery from dental amalgam.
\end{abstract}

Descriptors: Dental amalgam; Dental waste; Mercury.

\author{
Corresponding author: \\ José Mauro Granjeiro \\ Rua 47, n. 53, Casa 6 - Condomínio Ubá \\ Fazendinha, Itaipú \\ Niterói - RJ - Brazil \\ CEP: 24342-270 \\ E-mail:jmgranjeiro@vm.uff.br
}




\section{Introduction}

Human activities in general often produce residues, some hazardous to the environment and to mankind. Factors related to population growth and industrial development have increased the production of residues worldwide. ${ }^{1}$

In the last decades, the need for residue control has become evident in order to prevent continuous degradation of natural elements such as water, air and soil. The effects of such indiscriminate pollution affecting mankind have led society to a more conscious thinking of the real danger for future generations. ${ }^{1}$

Several institutions, including Universities, have tried to manage and treat their residues in an attempt to reduce the impact on the environment, leading to promotion of a responsible environmental conscience and triggering critical thinking by students, faculty and staff members regarding appropriate residue disposal. ${ }^{2}$

The impact caused on the environment today is predicted by laws and strict rules which converge to procedures for the preservation of life in general. ${ }^{3}$

In Brazil, the tolerance limits for the presence of mercury in the environment and in live organisms are established by Regulatory Norms (RNs) of the Ministry of Labor and World Health Organization (WHO) and ABNT (Brazilian Association of Technical Rules). ${ }^{4}$

According to NBR 10004:2004, residues produced can be classified according to the risk or danger they pose to health and to the environment: Type I - Dangerous, Type II - Not dangerous. Type II residues can be further subdivided in Not Inert (Type IIA) and Inert (Type IIB). ${ }^{4}$

Regulatory rule NR15, established by Rule 3214 in June 8, 1978, of the Ministry of Labor, considers mercury as one of the main hazardous agents to the operator's health, with the highest degree of insalubrity. The tolerance limit is the concentration - either maximum or minimum - related to the nature and length of time of exposure to the agent, which will not lead to any health problem during the individual's work life. The maximum limit of exposure to metallic mercury for a 48 hour working week is $0.0040 \mathrm{mgHg} / \mathrm{m}^{3} .^{3}$
Recent laws regarding environmental policy have included the concept of crime against the environment (Law of Environmental Crimes n. 9.605 of February 12, 1998), proposing civil and criminal lawsuits against those responsible for environmental crimes, whether as individuals or as institutions or enterprises. ${ }^{5}$

In dental offices, amalgam is a solid residue of heavy metals such as mercury $(50-55 \%)$, silver $(32.5-37 \%)$, tin (12-14.5\%), copper (0-3\%) and zinc $(0-1 \%)$. Mercury, a heavy liquid metal, is considered highly toxic to human beings and to the environment, presenting a fusion point of $38.6^{\circ} \mathrm{C}$ and boiling point at $356^{\circ} \mathrm{C}$ releasing clear and odorless vapors, of easy penetration through respiratory airways. ${ }^{6,7}$

Dental health professionals are exposed daily to mercury and its risks of contamination, which may occur through manipulation of amalgam, direct contact with the metal dropped accidentally, removal of excess mercury from the amalgam restoration, leaking amalgam devices and ultrasound condensers. Failures in the aspiration system while removing amalgam restorations ${ }^{8}$ or vapors from remainders of inadequately stored amalgam in dental offices ${ }^{9}$ also represent sources of contamination.

In that context, methods for amalgam recovery have been proposed, and Valenzuela ${ }^{10}$ (1985) has suggested application of a method for the recovery of the mercury present in amalgam residues in private dental offices. The method combines the use of high temperatures and a toxic reagent (potassium cyanide). In 1998, Pécora et al. ${ }^{11}$ proposed a simpler method for recovery of mercury and silver present in amalgam using distillation of the mercury and extraction of the silver in concentrated nitric acid. Although not using cyanide in this procedure, high temperatures and an average processing time of 4 hours were necessary to process $200 \mathrm{~g}$ of amalgam. This method was still considered as posing an elevated occupational risk, due to the manipulation of instruments in direct flame and to the gas exposure during mercury distillation.

Therefore, the purpose of this study was to develop and evaluate an alternative method for mercury recovery that would decrease processing time. 


\section{Material and Methods Material}

Amalgam residues were collected from the dental clinics of the School of Dentistry of Bauru (FOB), from the Rehabilitation of Craniofacial Anomalies Hospital (HRAC) and from the laboratory of Dental Materials, FOB, University of São Paulo, Bauru, SP, Brazil. In 10 months, 2 kilograms of amalgam residues were collected and sent to the Laboratory of Chemical Residues (LCR), University of São Paulo in Bauru.

\section{Methods}

\section{Recovery of mercury from amalgam}

The process of mercury recovery from amalgam residues was performed through the technique of vacuum distillation. Individual protection equipment such as filter masks against mercury vapors and particles, protection goggles and gloves were used at all times to avoid contamination during amalgam manipulation.

The process of distillation was carried out in a hood with exhaustion escape and started by elevating the temperature of the amalgam container, a $500 \mathrm{ml}$ Kjeldajhl flask (Corning, Big Flats, New York, USA) with an electric mantle until approximately $400^{\circ} \mathrm{C}$, where the distilled mercury was further collected in a kitasato kept in ice to facilitate mercury condensation. The system presents a safety device, a con- nection to another kitasato containing $1 \% \mathrm{HNO}_{3}$, which allows retention of the mercury vapors that might not have been condensed. The low pressure in the system is kept by a vacuum bomb which is protected by a filter containing sulfur, eliminating the risk of environmental contamination.

The 2,000 $\mathrm{g}$ of amalgam to be processed were divided in 5 samples of $200 \mathrm{~g}, 6$ samples of $150 \mathrm{~g}$ and one sample of $100 \mathrm{~g}$, and further submitted to fractioned distillation. Mercury distillation results in a solid residue composed mainly by silver and other metals that constitute amalgam, and mercury, which is distilled twice by the same method.

\section{Results}

Graph 1A shows the amount of mercury recovered and the remaining solid residue for each process. A total of $879.5 \mathrm{~g}$ of mercury were recovered with approximately $90 \%$ of efficiency (minimum of $83 \%$ and maximum of $92 \%$ ), considering that mercury represents $50 \%$ of the amalgam mass. The average processing time for this step was 30 minutes. Bi-distillation of distilled mercury recovered $845.4 \mathrm{~g}$ (Graph 1B), with an average efficiency of $96 \%$ in 83 minutes.

\section{Discussion}

Excessive exposure to any form of mercury (vapors, liquids) may cause severe damage to the en-

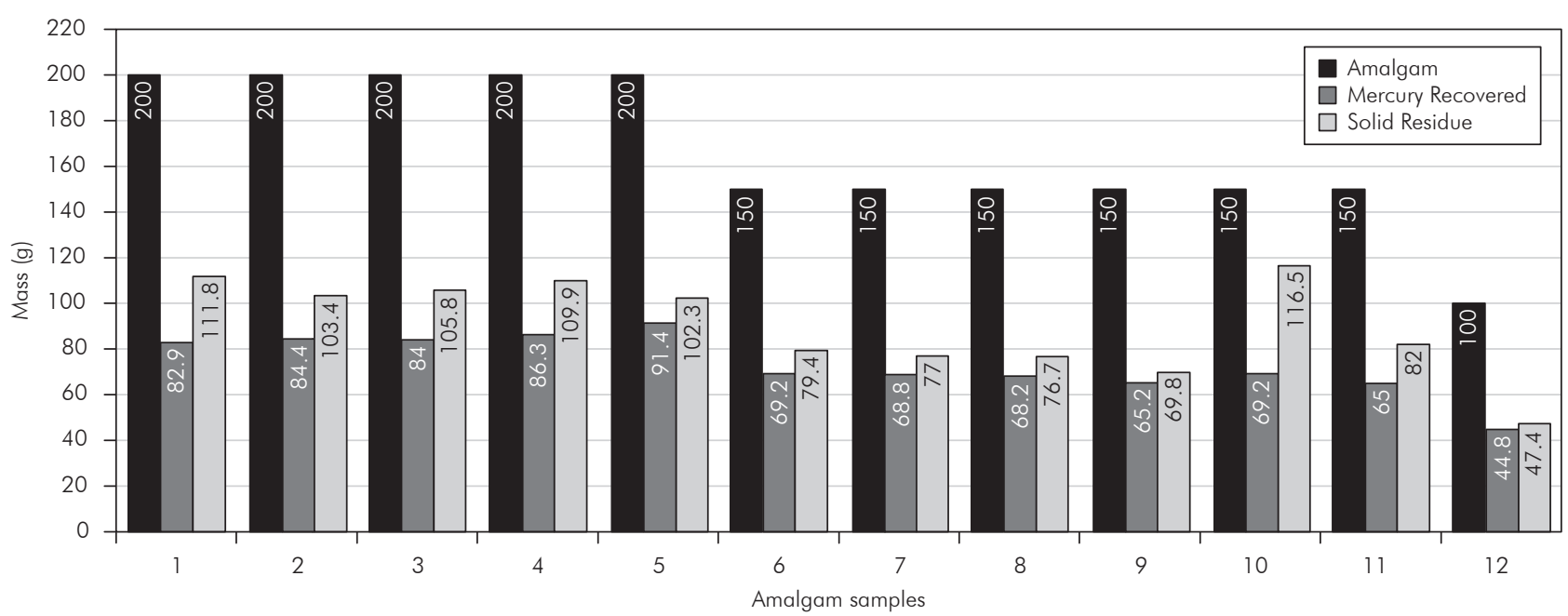

Graph 1A - Recovery of mercury from dental amalgam by distillation. Mass of amalgam processed and mercury and solid residues recovered for the 12 amalgam samples. 


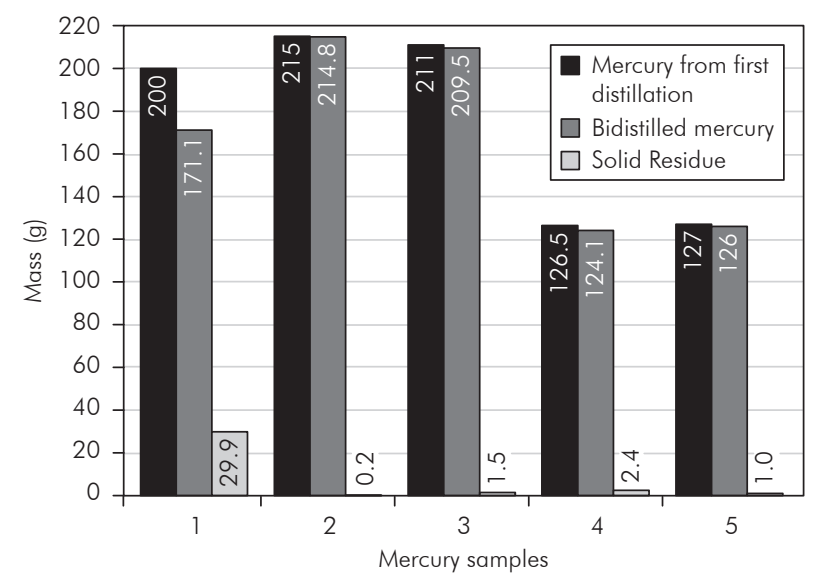

Graph 1B - Recovery of mercury from dental amalgam by distillation. Mass of distilled mercury, bi-distilled mercury and solid residues for 5 mercury samples.

vironment due to its accumulation and biotransformation in methyl-mercury, the most toxic form. ${ }^{12}$ Contamination of seaweeds and plants, basis of the natural food chain, leading to the eventual accumulation of mercury in humans can cause serious sequelae such as damage to the central nervous system, characterized by loss of sensation at the extremities of the hands and feet and in areas around the mouth (paresthesia), loss of coordination in gait (ataxia), slurred speech (dysarthia), vision (concentric constriction of the visual field) and hearing impairments. Severe poisoning can cause blindness, coma and death. ${ }^{13}$ Mercury is widely known as teratogenic and genotoxic. ${ }^{14}$

Control of mercury residues is extremely important. Since amalgam is still used in dental schools and private offices, proper destination should be given to amalgam residues to avoid environmental contamination. Approximately $30 \%$ of amalgam residues are discarded in the ordinary trash without proper treatment, and thus methods for mercury recovery and return of this material to the production line are essential. ${ }^{15}$

Saquy, Pécora ${ }^{16}$ (1996) emphasize that some procedures must be carried out in order to avoid contamination, such as:

a. mercury spills in the office floor and furniture must be avoided;

b. use of gloves, face mask and protection goggles;

c. the office must have an exhaustion system; d. the mercury/alloy ratio must be reduced;

e. use of amalgam devices without escape of mercury;

f. automatic condensers must not be used;

g. failures in the aspiration system must be avoided;

h. use of potent aspiration while removing restorations and also new drills under copious cold irrigation.

Nevertheless, one of the greatest problems is the destination of the amalgam removed from old restorations or the excess amalgam of a new restoration. It is not uncommon to observe that the final destination of the residue is the ordinary trash, in a clear violation of the current environmental legislation. In cities where selective trash collection is mandatory, residues are collected separately by special companies and are often discarded in sanitary deposits, without proper treatment and recovery, thus being substrate for the formation of hazardous compounds which may leak into the atmosphere contaminating soil and water.

Valenzuela ${ }^{10}(1985)$ proposed a method for recycling the mercury present in amalgam residues originated from dental offices. The method consisted in heating the residues at $650^{\circ} \mathrm{C}$, causing evaporation of mercury and condensation in another refrigerated container. This mercury presented high levels of impurity and organic elements which would be further removed with washes in 1\% nitric acid solution and in $1 \%$ potassium cyanide and sodium peroxide solutions diluted in distilled water. Thereafter, the material was dried and distilled, resulting in a $99 \%$ pure mercury.

This technique was modified by Pécora et al. ${ }^{11}$ (1998) by adding the process of vacuum distillation to mercury recovery, thus eliminating the use of toxic reagents as cyanide and avoiding production of more residues. Elevation of temperature was performed with direct flame and the process lasted 4 to 5 hours. Replacing this system by an electric mantle yielded great advantages since the distillation process was accelerated up to 10 times and the risks of accidents were reduced.

It is important to consider that reselling the recovered mercury is not enough to cover the costs of 
the process. However, as described by Calderoni ${ }^{17}$ (1997) the economic and environmental costs avoided by the process of residue recovery refer to the decrease in the need for prime material acquisition and also of discarding the residues obtained, resulting in a reduction of the environmental impact.

Since dental amalgam is still widely used in Dentistry, discarding procedures must follow adequate protocols, sending the residues to centers for mercury recovery and silver such as LAGRO ( $h t t p: / / w w w$. forp.usp.br/restauradora/lagro) and LCR (bttp:// $w w w . f o b . u s p . b r / l r q)$ in Bauru, in order to avoid damage to the environment or environmental crime lawsuits, with the eventual shutting down of dental offices.

It seems obvious that environmental conscience and the commitment to maintaining it are still far from acknowledged by the population in general. However, it is necessary to implement simple yet efficient programs for residue recovery. Some important aspects such as storage of amalgam residues in appropriate flasks and low temperatures (refrigerator or freezer) should be considered in order to minimize the risk of mercury volatilization. Studies have suggested that the most efficient method for storing amalgam, retaining mercury vapors, would be glyc-

\section{References}

1. Bendassolli JA, Máximo E, Tavares GA, Ignoto RF. Gerenciamento de Resíduos Químicos e Águas Servidas no Laboratório de Isótopos Estáveis no CENA/USP. Quím Nova. 2003;26(4):612-7.

2. Afonso JC, Noronha LA, Felipe RP, Freidinger N. Gerenciamento de resíduos laboratoriais: recuperação de elementos e preparo para descarte final. Quím Nova. 2003;26(4):602-11.

3. Malthus TR. Economia. São Paulo: Ática; 1982.

4. ABNT - Associação Brasileira de Normas Técnicas NBR 10004:2004. Resíduos sólidos: classificação. São Paulo: ABNT; 2004.

5. Segurança e medicina do trabalho. $49^{a}$ ed. São Paulo: Atlas; 1997. (Manuais de legislação Atlas).

6. Glina DMR, Andrade EMOAC, Satut BTG. Mercúrio metálico em consultórios odontológicos: estudo de caso na rede de saúde de São Paulo. Revista do Projeto de Cooperação Técnica BrasilItália. 1998;(Espec):155-8.

7. Saquy PC, Silva RS, Neto MDS, Pécora JD. Apresentação de um método, qualitativo, de identificação de vapor de mercúrio. Rev Paul Odontol. 1997;19(2):6-8. erin. ${ }^{18}$ However, Saquy ${ }^{8}$ (1996) observed that radiographic solution followed by water were more efficient. Nevertheless, either glycerin or radiographic solution would sum up to more residues. Due to the low efficacy of water, we should evaluate other possibilities such as freezing the residue to minimize formation of mercury vapors.

\section{Conclusion}

The modifications proposed allowed a significant reduction in the time required for processing dental amalgam and posterior mercury recovery with a high level of purity. In addition, the modifications greatly reduced the exposure of operators to physical, chemical and ergonomic risks inherent to the original method. Replacing the fossil, organic, finite energy source by an electric source more appropriate for preserving the environment resulted in a significant improvement of the procedure for mercury recovery from dental amalgam.

\section{Acknowledgements}

We wish to thank the Brazilian Funding Agencies for supporting this research: Fapesp (04/002655); Direction of FOB and PRP-USP. Special thanks to Prof. Dr. Jesus Djalma Pécora.

8. Saquy PC. Identificação quantitativa de vapor de mercúrio captado de resíduo de amálgama de prata em diferentes meios de armazenagem [Tese de Livre-Docência]. Ribeirão Preto: Faculdade de Odontologia da USP; 1996.

9. Rupp NW, Paffenbarger GC. Significance to health of mercury used in dental practice: a review. J Am Dent Assoc. 1971;82(6):1401-7.

10. Valenzuela NP. Tratamiento de los desechos de amalgama: una forma de disminuir la contaminación ambiental por el mercurio. Odontol Chil. 1985;33(1):17-20.

11. Pécora JD, Silva RS, Souza RA, Guimarães LFL, Shuhama T. Reciclaje de los residuos de amalgama dental mediante la recuperación de mercurio y plata. Rev Fola/Oral. 1998;4(14):2347.

12. Boyd AS, Seger D, Vannucci S, Langley M, Abraham JL, King LE Jr. Mercury exposure and cutaneous disease. J Am Acad Dermatol. 2000;43(1 Pt 1):81-90.

13. Bakir F, Dambuji SF, Amin-Zaki L, Murthada M, Khalidi A, Al-Rawi NY et al. Methylmercury poisoning in Iraq. Science. 1973;181(96):230-40. 
- Optimizing the procedure for mercury recovery from dental amalgam

14. Hirata MH, Mancini Filho J. Manual de biossegurança. São Paulo: Manole; 2002.

15. Pécora JD. Guia Prático sobre resíduos de amálgama odontológico. [acesso 10 mar 2006]. Disponível em: http://www.forp. usp.br/restauradora/lagro/guia_pratico.html.

16. Saquy PC, Pécora JD. Orientação profissional em Odontologia. São Paulo: Santos; 1996.
17. Calderoni S. Os bilhões perdidos no lixo. São Paulo: Humanitas/FFLCH/USP; 1997.

18. Fortes CBB, Werner SM. Avaliação de meios para armazenagem de resíduos de amálgama de prata. Rev Fac Odontol Porto Alegre. 2000;40(2):36-40. 